\title{
New Developments in Nanomechanical Methods
}

\author{
JANELLE P. WHARRY (i] ${ }^{1,3}$ and MEGAN J. CORDILL ${ }^{2}$ \\ 1.-Purdue University, West Lafayette, IN 47906, USA. 2.-Erich Schmid Institute of Materials \\ Science, Austrian Academy of Science, Leoben, Austria. 3.-e-mail: jwharry@purdue.edu
}

Nanomechanical testing methods originated in the 1980 s with atomic force microscopy (AFM)-based indentation to probe the hardness and modulus of thin films. ${ }^{1,2}$ The subsequent development of standalone nanoindentation techniques resulted in an unprecedented, widespread expansion of the use of nanomechanical testing methods for a wide variety of materials-including metals and alloys, ceramics, biologic materials, and soft materials. Nanoindentation has also been uniquely applied to a wide variety of specimen configurations, including thin films, ${ }^{3,4}$ nanoparticles, ${ }^{5}$ composites, ${ }^{6}$ and surface layers such as tribologic coatings and ion-irradiated layers. ${ }^{7,8}$

The advent of site-specific focused ion beam (FIB) milling ${ }^{9}$ roughly 2 decades ago has enabled yet another rapid expansion of nanomechanical methods, specifically in situ mechanical tests conducted within a scanning electron microscope (SEM) using a depth-sensing holder. ${ }^{10,11}$ The method enables concurrent collection of load-displacement data and SEM resolution images or video of a specimen throughout the deformation process. In situ techniques offer transformative insight into deformation mechanisms and have thus been broadly adopted to test a wide range of materials in numerous configurations, including compression pillars, ${ }^{12-14}$ cantilevers or three-point bend beams, ${ }^{15-18}$ tensile bars, ${ }^{14,19}$ indentation, ${ }^{20-22}$ and creep. ${ }^{23}$ Within the past decade, development of depth-sensing transmission electron microscopic (TEM) in situ mechanical testing holders ${ }^{10}$ has further enhanced our ability to resolve and quantitatively understand nanomechanical phenomena. TEM in situ mechanical testing has been conducted in compression, ${ }^{24}$ tension, ${ }^{19,24}$ bending, ${ }^{25}$ and indentation ${ }^{26}$ modes to investigate a wide range of nanomechanical behaviors at the atomic through nano-scale, including

Janelle P. Wharry is the JOM advisor for the Nanomechanical Materials Behavior Committee of the TMS Materials Processing \& Manufacturing Division, and co-guest editor with Megan J. Cordill for the topic New Developments in Nanomechanical Methods in this issue. dislocation slip, ${ }^{27-29}$ twinning, ${ }^{30,31}$ diffusionless phase transformations, ${ }^{32}$ bubble shearing, ${ }^{30,33}$ and irradiation effects. ${ }^{26,34,35}$

Advancements in computation since the late 1990s have developed in concert with the aforementioned experimental methods. Finite element ${ }^{36}$ and phase field ${ }^{37,38}$ models have been integrated with one another to introduce microstructural awareness to stress and strain distributions in a specimen during deformation. ${ }^{39}$ These models complement SEM in situ nanomechanical methods. Discrete dislocation dynamics (DDD) $)^{40,41}$ and molecular dynamics (MD) ${ }^{42,43}$ simulations, on the other hand, complement TEM in situ nanomechanical testing by providing a fundamental understanding of the interaction of dislocations with the material microstructure during deformation.

All of these advancements in nanomechanical methods have required tight coupling of novel tools developed by researchers in industry, with applications refined at laboratories and in academia. In keeping with this trend, this JOM focus topic incorporates the latest developments from several industry leaders, with new methods developed by users across the research enterprise. This focus issue aims to further push the boundaries of nanomechanical methods to open new frontiers for nanomechanical testing, analysis, and understanding.

Several papers within this focus issue are centered around evaluating parameters or behaviors that have historically been difficult to measure. For example, activation energies and enthalpies are hard to measure but are necessary to understand deformation mechanisms. Authors Ovri and Lilleodden have developed a nanoindentation-based method that uses the well-known Portevin-Le Chanterlier (PLC) effect to estimate activation enthalpies in an Al-Mg alloy. The new approach, thoroughly examined with respect to strain rate, indentation depth, and indenter geometry, derives values that are in good agreement with known 
literature values. This new technique will enable further investigations into other materials that deform via PLC mechanisms.

Irradiation creep is another mechanical behavior that is difficult to measure. Specifically, neutronirradiated specimens contain high levels of radioactivity, making creep testing hazardous. While ionirradiated specimens have little to no radioactivity, they contain only a few- $\mu$ m-thick irradiated surface layer on which it is impossible to measure creep using conventional methods. In this issue, Bufford et al. present a first-of-its-kind TEM in situ tensile testing method for quantifying irradiation creep. They demonstrate the measurement of creep rate and compliance in a thin film of nanocrystalline $\mathrm{Zr}$. Their method presents an adaptable, cost-effective, and rapid way to screen the irradiation creep response of candidate materials for nuclear and irradiation environments.

The advancement of existing nanomechanical methods to gain deeper insight from results, or increase the fidelity of results, is also a central theme in this focus issue. Many nanomechanical methods used today are based on nanoindentation. While "simple" nanoindentation experiments to measure hardness and elastic modulus are still prevalent, nanoindenters themselves are continually being advanced. For example, by adding acoustic emission (AE) analysis, a better understanding and an even more complex interpretation of the resulting indentation load-displacement curves and scratch measurements can be made. Several examples where $\mathrm{AE}$ analysis is used are presented in the paper by Ctvrtlik and coworkers. The throughput of nanoindentation experiments can also be accelerated, enabling researchers to obtain greater confidence in results by acquiring larger data sets in a fraction of the time. The paper from Chen and coworkers presents a high-throughput nanoindentation setup that can be used to test structural materials at high temperatures and in vacuum; they demonstrate this system on an $\mathrm{Al}_{0-0.3} \mathrm{FeCrNiMn}$ high-entropy alloy.

Nanomechanical experiments on micro-sized cantilevers used to measure fracture toughness have also become commonplace. However, even though these experiments are relatively simple to perform with the correct instruments, problems often arise with having the appropriate crack stability necessary for compliance with the ASTM standard. Applied with elastic plastic fracture mechanics (EPFM), a chevron notch geometry can be used to improve crack stability for semi-brittle materials. $\mathrm{Li}$ and Armstrong provide a detailed and validated approach using a chevron notch to study size effects when using micro-sized cantilevers.

Specific applications or fields can have unique needs for nanomechanical method development, representing another common theme in this focus issue. In the polymer sciences, for example, one advanced method needed is the combination of atomic force microscopy (AFM) with dynamic mechanical analysis (DMA) to have a local quantitative viscoelastic analysis. The new method, described in the paper from Pittenger et al., was tested at two independent laboratories, is embedded into the force curve, and provides spectra for the storage modulus, loss modulus, and loss tangent with a spatial resolution of $10 \mathrm{~nm}$. With this new technique, previously inaccessible microscopic domains and interphases can now be examined. Power semiconductor devices also have unique nanomechanical testing needs because of their extreme temperature cycling during service. The paper from Moser et al. presents a novel experimental setup to conduct SEM in situ thermomechanical cycling of metallizations. They demonstrate this technique for a $\mathrm{Cu}$ metallization on a $\mathrm{Si}$ substrate by performing 12,000 stress cycles of $300^{\circ} \mathrm{C}$ temperature differences during $200-\mu$ s heating periods.

Finally, to continue advancing the frontiers of nanomechanical methods, computational models can be used to conceptualize the promising new techniques that have yet to be developed experimentally. The paper from Pal et al. uses molecular dynamics (MD) simulations of single-crystal $\mathrm{Mg}$ through a proposed new "nano-rolling" technique. Nano-rolling is a theorized nano-scale working technique that would pass a few-nanometer-thick film through a pair of few-nanometer-diameter rollers. Controlling the deformation rate could control the deformation mechanism, which could enable engineers to tailor the yield and ultimate tensile stresses of a material.

The following list summarizes the papers being published under the topic of "New Developments in Nanomechanical Methods". To read or download any of the papers, follow the URL http://link.springe r.com/journal/11837/71/10/page/ 1 to the table of contents page for the October 2019 issue (vol. 71, no. $10)$.

- "On the Estimation of Thermal Activation Parameters for Portevin-Le Chatelier Effect from Nanoindentation Data" by Henry Ovri and Erica T. Lilleodden

- "Application of In Situ TEM to Investigate Irradiation Creep in Nanocrystalline Zirconium" by Daniel C. Bufford, Christopher M. Barr, Baoming Wang, Khalid Hattar, and Aman Haque

- "High-Resolution Acoustic Emission Monitoring in Nanomechanics" by Radim Ctvrtlik, Jan Tomastik, Lukas Vaclavek, Ben David Beake, Adrian Jeffrey Harris, Alberto Sanchez Martin, Michal Hanak, and Petr Abrham

- "High-Throughput Nanomechanical Screening of Phase-Specific and Temperature-Dependent Hardness in $\mathrm{Al} x \mathrm{FeCrNiMn}$ High Entropy Alloys" by Youxing Chen, Eric Hintsala, Nan Li, Bernard R. Becker, Justin Cheng, Bartosz Now- 
akowski, Jordan Weaver, Douglas Stauffer, and Nathan A. Mara

- "Evaluation of Fracture Toughness Measurements Using Chevron-Notched Silicon and Tungsten Micro-Cantilevers" by B.-S. Li, T.J. Marrow, S.G. Roberts, and D.E.J. Armstrong

- "Nanoscale DMA with the Atomic Force Microscope: A New Method for Measuring Viscoelastic Properties of Nanostructured Polymer Materials" by Bede Pittenger, Sergey Osechinskiy, Dalia Yablon, and Thomas Mueller

- "A Novel Setup for In Situ Monitoring of Thermomechanically Cycled Thin Film Metallizations" by Sebastian Moser, Gerald Zernatto, Manuel Kleinbichler, Michael Nelhiebel, Johannes Zechner, Megan J. Cordill, and Reinhard Pippan

- "Nano-rolling: Roller Speed-Dependent Morphological Evolution and Mechanical Properties Enhancement in Nanoscale Mg" by K. Vijay Reddy and Snehanshu Pal

\section{ACKNOWLEDGEMENTS}

JPW acknowledges support from the National Science Foundation CAREER award DMR-1752636 and US DOE Office of Nuclear Energy contract DENE0008758.

\section{REFERENCES}

1. W.D. Nix, Metall. Trans. A 20, 2217 (1989).

2. W.C. Oliver and G.M. Pharr, J. Mater. Res. 7, 1564 (1992).

3. M.J. Cordill, M.D. Chambers, M.S. Lund, D.M. Hallman, C.R. Perrey, C.B. Carter, A. Bapat, U. Kortshagen, and W.W. Gerberich, Acta Mater. 54, 4515 (2006).

4. T.F. Page and S.J. Bull, Philos. Mag. 86, 5331 (2006).

5. W. Gerberich, W. Mook, C. Perrey, C. Carter, M. Baskes, R. Mukherjee, A. Gidwani, J. Heberlein, P. McMurry, and S. Girshick, J. Mech. Phys. Solids 51, 979 (2003).

6. R.F. Gibson, Compos. Sci. Technol. 105, 51 (2014).

7. W.W. Gerberich, N.I. Tymiak, D.E. Kramer, A. Daugela, J. Jungk, and M. Li, Philos. Mag. A 82, 3349 (2002).

8. C.K. Dolph, D.J. da Silva, M.J. Swenson, and J.P. Wharry, J. Nucl. Mater. 481, 33 (2016).

9. L.A. Giannuzzi, J.L. Drown, S.R. Brown, R.B. Irwin, and F.A. Stevie, Microsc. Res. Tech. 41, 285 (1998).

10. M. Legros, D.S. Gianola, and C. Motz, MRS Bull. 35, 354 (2010).

11. A. Barnoush, P. Hosemann, J. Molina-Aldareguia, and J.M. Wheeler, MRS Bull. 44, 471 (2019).

12. S. Romeis, J. Paul, M. Ziener, and W. Peukert, Rev. Sci. Instrum. 83, 095105 (2012).

13. P. Franciosi, L.T. Le, G. Monnet, C. Kahloun, and M.-H. Chavanne, Int. J. Plast 65, 226 (2015).

14. J.Y. Kim, D. Jang, and J.R. Greer, Acta Mater. 58, 23552363 (2010).
15. H. Zhou, L. Mishnaevsky, P. Brøndsted, J. Tan, and L. Gui, Chin. Sci. Bull. 55, 1199 (2010).

16. S. Orso, U.G.K. Wegst, and E. Arzt, J. Mater. Sci. 41, 51225126 (2006).

17. S. Vlassov, B. Polyakov, L.M. Dorogin, M. Antsov, M. Mets, M. Umalas, R. Saar, R. Lõhmus, and I. Kink, Mater. Chem. Phys. 143, 1026 (2014).

18. J.-P. Zuo, X.-S. Wang, and D.-Q. Mao, Eng. Fract. Mech. 131, 504 (2014)

19. M.A. Haque and M.T.A. Saif, Exp. Mech. 42, 123 (2002). h ttps://doi.org/10.1007/BF02411059.

20. A.M. Minor, J.W. Morris, and E.A. Stach, Appl. Phys. Lett. 79, 1625 (2001)

21. K.A. Rzepiejewska-Malyska, G. Buerki, J. Michler, R.C. Major, E. Cyrankowski, S.A.S. Asif, and O.L. Warren, $J$. Mater. Res. 23, 1973 (2008).

22. K.S. Mao, C. Sun, Y. Huang, C.-H. Shiau, F.A. Garner, P.D. Freyer, and J.P. Wharry, Materialia 5, 100208 (2019).

23. J.L. Walley, R. Wheeler, M.D. Uchic, and M.J. Mills, Exp. Mech. 52, 405 (2012).

24. J.T.M. De Hosson, Microsc. Res. Tech. 72, 250-260 (2009).

25. M.S. Wang, I. Kaplan-Ashiri, X.L. Wei, R. Rosentsveig, H.D. Wagner, R. Tenne, and L.M. Peng, Nano Res. 1, 22 (2008).

26. K.H. Yano, S. Thomas, M.J. Swenson, Y. Lu, and J.P. Wharry, J. Nucl. Mater. 502, 201 (2018).

27. Y.C. Hsieh, L. Zhang, T.F. Chung, Y.T. Tsai, J.R. Yang, T. Ohmura, and T. Suzuki, Scr. Mater. 125, 44 (2016).

28. L. Zhang, N. Sekido, and T. Ohmura, Mater. Sci. Eng. A 611, 188 (2014)

29. V. Samaee, R. Gatti, B. Devincre, T. Pardoen, D. Schryvers, and H. Idrissi, Sci. Rep. 8, 1 (2018).

30. W.Z. Han, M.S. Ding, R.L. Narayan, and Z.-W. Shan, Adv. Eng. Mater. 19, 1700357 (2017).

31. J. Jeong, M. Alfreider, R. Konetschnik, D. Kiener, and S.H. Oh, Acta Mater. 158, 407 (2018).

32. J. Liu and D. Kaoumi, Mater. Charact. 136, 331 (2018).

33. W.Z. Han, J. Zhang, M.S. Ding, L. Lv, W.H. Wang, G.H. Wu, Z.W. Shan, and J. Li, Nano Lett. 17, 3725 (2017).

34. D. Kiener, P. Hosemann, S.A. Maloy, and A.M. Minor, Nat. Mater. 10, 608 (2011).

35. K.H. Yano, M.J. Swenson, Y. Wu, and J.P. Wharry, J. Nucl. Mater. 483, 107 (2017).

36. W.K. Liu, H.S. Park, D. Qian, E.G. Karpov, H. Kadowaki, and G.J. Wagner, Comput. Methods Appl. Mech. Eng. 195, 1407 (2006).

37. T. Hirouchi, T. Takaki, and Y. Tomita, Comput. Mater. Sci. 44, 1192 (2009)

38. Y. Wang and J. Li, Acta Mater. 58, 1212 (2010).

39. A. Yamanaka, T. Takaki, and Y. Tomita, Int. J. Mech. Sci. $52,245(2010)$.

40. G. Po, M.S. Mohamed, T. Crosby, C. Erel, A. El-Azab, and N Ghoniem, JOM 66, 2108 (2014).

41. F. Akasheh, H.M. Zbib, J.P. Hirth, R.G. Hoagland, and A. Misra, J. Appl. Phys. 101, 084314 (2007).

42. D. Wolf, V. Yamakov, S.R. Phillpot, A. Mukherjee, and H. Gleiter, Acta Mater. 53, 1 (2005).

43. T. Zhu and H. Gao, Scr. Mater. 66, 843 (2012).

Publisher's Note Springer Nature remains neutral with regard to jurisdictional claims in published maps and institutional affiliations. 